\title{
GREEN BARLEY AS AN INGREDIENT IN PASTA: ANTIOXIDANT ACTIVITY AND SENSORY CHARACTERISTICS EVALUATION
}

\author{
Eva IVANIŠOVÁl`,Martin KOŠEC ${ }^{1}$, Ján BRINDZA², Olga GRYGORIEVA ${ }^{3}$, Marián TOKÁR ${ }^{1}$
}

\begin{abstract}
Summary: The aims of the present study was to determine antioxidant activity, sensory properties as well as total polyphenol, flavonoid and chlorophyll content of raw and cooked pasta enriched by 1\%, 3\% and 5\% addition of green barley powder. Results of antioxidant activity showed that increase of green barley addition increase antioxidant activity of pasta. The values in raw pasta obtained by DPPH ranged from 1.17 (control) to 1.81 (5\% addition) mg TEAC/g DM, after cooking values ranged from 0.82 (control) to 1.59 (5\% addition) $\mathrm{mg}$ TEAC/g DM. Similar tendency was signed by molybdenum reducing antioxidant power method. In enriched pasta was also found higher content of total polyphenol (0.19 in control raw sample and $1.81 \mathrm{mg} G A E / g ~ D M$ in pasta with $5 \%$ of green barley addition; values of cooked pasta ranged from 0.10 in control sample to $0.73 \mathrm{mg} G A E / g$ DM in pasta with $5 \%$ of green barley addition) as well as total flavonoid content (results of raw pasta were from 0.00 in control sample to $0.41 \mathrm{mg} \mathrm{QE/g} \mathrm{DM} \mathrm{in} \mathrm{pasta} \mathrm{with} \mathrm{5 \%} \mathrm{of} \mathrm{green} \mathrm{barley} \mathrm{addition;} \mathrm{values} \mathrm{of} \mathrm{cooked} \mathrm{pasta} \mathrm{were} \mathrm{from} 0.00$ in control sample to 0.29 $\mathrm{mg}$ QE/g DM in variant with 5\% green barley). Green barley also enriched pasta for chlorophyll with the best results in 5\% addition. From prepared variants of enriched pasta the best overall acceptability was sign in 3\% of green barley addition. Pastas enriched with plant-derived bioactive compounds such as green barley may confer health benefits to consumers.
\end{abstract}

Key words: enriched pasta, polyphenols, flavonoids, chlorophyll

\section{INTRODUCTION}

Nowadays, a growing demand for healthy food, such as products enriched with plant bioactive compounds and low energy, has been observed. Cereal-based foods are of primarily importance in human nutrition; since they represent 30-70\% of daily energy intake (WHO/FAO, 2003). Pasta is a widely consumed food because of its low cost, easy preparation, and long shelf life. High quality pasta is manufactured using durum wheat semolina because of its very good cooking quality and high consumer acceptance (Biernacka et al., 2017). However in Slovakia is more traditional prepare pasta from Triticum aestivum L. flour type T650 due to the price and also agro technical causes, because Triticum durum L. is grown in Slovakia only in small amount. Pasta may represent an excellent model food vehicle for the addition of specific nutrients through incorporation of various products (eggs, milk powder, vegetables, fiber, medicinal herbs, and so on) in a targeted food product to enhance nutritional quality, improve health condition and reduce the risk of diseases (Tazrart et al., 2016). Barley (Hordeum vulgare L.) leaf is the one of the green grasses, and is a well-known component of green-colored powders, named "Zelený jačmeň" in Slovakia and "Aojiru" in Japan. Because of the greater nutritional value, the leaves of barley are beneficial to human health when harvested at a young age (usually within 2 weeks after seeding) (Kim et al., 2017). Young green barley leaves are a good natural source of vitamins and minerals, and their juice is widely consumed as a functional food for health reasons mainly in Japan, but this product starts be very popular also in Europe (Yamaura et al., 2015).

The main aim of present study was to prepare pasta enriched with green barley powder (1, 3 and 5\%) and subsequently determine sensory and biological activity of raw and cooked pasta.

\footnotetext{
${ }^{1}$ Eva Ivanišová, MSc, PhD. Assistant Professor, Martin Košec, MSc Teaching Assistant, Marián Tokár, MSc, PhD. Junior Research Scientist, Department of Plant Storage and Processing, Faculty of Biotechnology and Food Sciences, Slovak University of Agriculture in Nitra, Tr. A. Hlinku 2, Slovakia.

${ }^{2}$ Ján Brindza, MSc, CSc. Associated Professor, Institute of Biodiversity Conservation and Biosafety, Faculty of Agrobiology and Food Resources, Slovak University of Agriculture in Nitra, Tr. A. Hlinku 2, Slovakia.

${ }^{3}$ Olga Grygorieva MSc, PhD. Assistant Professor, M.M. Gryshko National Botanical Garden of Ukraine of National Academy of Sciences, Kyiv, Ukraine

`Corresponding author: Eva Ivanišová, e-mail: eva.ivanisova@uniag.sk, +421376414421
} 


\section{MATERIAL AND METHODS}

Material. Green barley powder (100\% from bio production Vegafit, Germany; composition per $100 \mathrm{~g}$ : proteins $29 \mathrm{~g}$, fat $-5 \mathrm{~g}$, sugars $-3.4 \mathrm{~g}$, dietary fiber $-39 \mathrm{~g}$ ) was purchased from local market as well as ingredients for preparing of pasta (flour T-650, eggs, salt). All chemicals used in this work were of analytical grade and purchased from Sigma-Aldrich (USA) and CentralChem (SK).

Pasta making process. Pasta samples were produced using an extruder (Gina, Italy) for the production of the extruded pasta. Here, $500 \mathrm{~g}$ flour type T-650 were mixed with green barley powder (1, 3 and 5\%), one egg (60 g), salt (7 g) and tap water in a rotary-shaft mixer at $25^{\circ} \mathrm{C}$ for $20 \mathrm{~min}$, to obtain dough with $30 \%$ moisture content. A screw (length, $30 \mathrm{~cm}$; diameter, $5.5 \mathrm{~cm}$ ) that ended with a bronze die (hole diameter, $1.70 \mathrm{~mm}$ ) was used to extrude the dough into a elbows shape. The screw speed was $50 \mathrm{rpm}$. The extrusion pressure was approximately $3.4 \mathrm{bar}$, and the temperature of the pasta after the extrusion was $27 \mathrm{C}$ to $28^{\circ} \mathrm{C}$. Extruded pasta was dry in drying chamber (8 hours at $40^{\circ} \mathrm{C}$ ) to final moisture content approximately $12.5 \%$. Before the analyzing pasta was homogenized to particle size $0.5 \mathrm{~mm}$.

Extract preparation. $0.25 \mathrm{~g}$ of sample was extracted with $20 \mathrm{~mL}$ of $80 \%$ ethanol for 24 hours $\left(25^{\circ} \mathrm{C}\right)$. After centrifugation at $4000 \mathrm{~g}$ (Rotofix $32 \mathrm{~A}$, Hettich, Germany) for $10 \mathrm{~min}$, the supernatant was used for measurement (antioxidant activity, polyphenols, flavonoids). Extraction was carried out in triplicate.

For chlorophyll determination $1 \mathrm{~g}$ of sample and $80 \%$ acetone were added into the mortar and the sample was completely broken into pieces $(0.5 \mathrm{~mm})$. The obtained extract was eluted with $80 \%$ acetone and filtered into $50 \mathrm{~mL}$ flasks through a common filter paper (Whatman $1 ; 11 \mu \mathrm{m}$ ).

Radical scavenging activity. Radical scavenging activity of samples was measured using 2,2-diphenyl-1picrylhydrazyl (DPPH) (Yen and Chen, 1995). Absorbance of the reaction mixture was determined using the spectrophotometer Jenway (6405 UV/Vis, England) at $515 \mathrm{~nm}$. Trolox (6-hydroxy-2,5,7,8-tetramethylchroman-2carboxylic acid) was used as the standard and the results were expressed in $\mathrm{mg} / \mathrm{g}$ Trolox equivalents.

Molybdenum reducing antioxidant power method. Molybdenum reducing antioxidant power method of samples was measured according Prieto et al., (1999) method with a slight modification. Absorbance of the reaction mixture was determined using the spectrophotometer Jenway (6405 UV/Vis, England) at $700 \mathrm{~nm}$. Trolox (6-hydroxy-2,5,7,8tetramethylchroman-2-carboxylic acid) was used as the standard and the results were expressed in mg/g Trolox equivalents.

Total polyphenol content. Total polyphenol content of extracts was measured by the method of Singleton and Rossi, (1965) using Folin-Ciocalteu reagent. Absorbance of the reaction mixture was determined using the spectrophotometer Jenway (6405 UV/Vis, England) at $700 \mathrm{~nm}$. Gallic acid was used as the standard and the results were expressed in $\mathrm{mg} / \mathrm{g}$ gallic acid equivalents.

Total flavonoid content. Total flavonoids were determined using the modified method of Lamaison and Carnat (Quettier - Deleu et al., 2000). Absorbance of the reaction mixture was determined using the spectrophotometer Jenway (6405 UV/Vis, England) at $405 \mathrm{~nm}$. Quercetin was used as the standard and the results were expressed in $\mu g^{\prime} g$ quercetin equivalents.

Total chlorophyll content. Total chlorophyll content was determined spectrophotometrically according to Lichtenthaler a Wellbum, (1983) method. Absorbance of the reaction mixture was determined using the spectrophotometer Jenway (6405 UV/Vis, England) at 649 and $664.5 \mathrm{~nm}$. Results were expressed in $\mathrm{mg}^{\prime} \mathrm{g}$.

Sensory evaluation. The sensory evaluation was carried out by 20 judges in the age group 20-60 years comprising of students and consumers. A nine-point hedonic scale was used to evaluate smell, green barley smell presence, green barley smell intensity, foreign smell, taste, green barley taste presence, green barley taste intensity, aftertaste, overall acceptability.

Statistical analysis. The basic statistical analyzes were realized in sas programming packages (THE SAS SYSTEM V 9.2.). Correlation coefficients were calculated by CORR analysis (SAS, 2009).

\section{RESULTS AND DISCUSSION}

Radical scavenging activity. The highest activity (Tab. 1) in raw enriched pasta was detected in pasta with 5\% green barley addition. Results were compared with control sample without addition, in which was found the lowest activity. Prepared raw pasta was cooked and after this process was also detected antioxidant activity. Antioxidant activity of pasta after boiling process decreased, which was no surprising because high temperature decrease amount 
of biologically active compounds, but after boiling process enriched pasta had better activity with compare to control sample, when activity was not detected. Boroski et al., (2011) determined antioxidant activity of pasta enriched by oregano and carrot leaf and found better activity with compared to control without addition.

Table 1. Radical scavenging activity of prepared pasta (dry matter)

\begin{tabular}{ccc}
\hline \hline Pasta sample & DPPH [mg TEAC/g] & DPPH [mg TEAC/g] \\
Raw pasta & Cooked pasta \\
\hline Control sample & $1.17 \pm 0.47$ & $0.83 \pm 0.06$ \\
$\mathbf{1 \%}$ green barley addition & $1.51 \pm 0.07$ & $1.51 \pm 0.07$ \\
$\mathbf{3 \%}$ green barley addition & $1.52 \pm 0.07$ & $1.40 \pm 0.03$ \\
$\mathbf{5 \%}$ green barley addition & $1.81 \pm 0.12$ & $1.59 \pm 0.04$ \\
\hline \hline
\end{tabular}

TEAC - Trolox equivalent antioxidant capacity; \pm standard deviation

Molybdenum reducing antioxidant power method. Similar tendency like using radical scavenging activity was observed using molybdenum reducing antioxidant power method (Tab. 2). Control sample without enrichment showed the lowest activity. Increasing addition of green barley powder increased antioxidant activity measured with this method, with the best values in 5\% green barley addition pasta - raw (21.96 mg TEAC/g) and cooked (12.64 mg TEAC/g). Higher antioxidant activity of enriched pasta is due to antioxidant from green barley. Pauličková et al., (2006) reported that green barley leaves contains significant quantities of calcium, copper, iron, magnesium, potassium, zinc, $\beta$-carotene, folate, pantothenic acid, vitamins $\mathrm{B}_{1}, \mathrm{~B}_{2}, \mathrm{~B}_{6}, \mathrm{C}$, and $\mathrm{E}$, superoxide dismutase, catalase, carotenoids and chlorophyll. Seczyk et al., (2015) evaluated pasta with addition of parsley leaves powder in amount $1 \%$ and $4 \%$. Their results showed that parsley similarly like green barley in our study increased the antioxidant activity (FRAP method) of pasta with the best results in 4\% parsley addition.

Table 2. Molybdenum reducing antioxidant power (MRAP) of prepared pasta (dry matter)

\begin{tabular}{ccc}
\hline \hline Pasta sample & MRAP [mg TEAC/g] & MRAP [mg TEAC/g] \\
Raw pasta & Cooked pasta \\
\hline Control sample & $13.34 \pm 1.16$ & $5.02 \pm 0.93$ \\
$\mathbf{1 \%}$ green barley addition & $13.69 \pm 0.37$ & $9.13 \pm 0.31$ \\
$\mathbf{3 \%}$ green barley addition & $14.62 \pm 0.68$ & $11.71 \pm 1.29$ \\
$\mathbf{5 \%}$ green barley addition & $21.96 \pm 1.01$ & $12.64 \pm 1.41$ \\
\hline \hline
\end{tabular}

TEAC - Trolox equivalent antioxidant capacity; \pm standard deviation

Total polyphenol content. Polyphenols are ubiquitous secondary metabolites in plants. They are known to have antioxidant activity and it is likely that the activity of these extracts is due to these compounds (Tepe et al., 2006). Total polyphenol content in raw and cooked pasta was the highest in pasta with $5 \%$ green barley addition. The lowest content (Tab. 3) was found in control sample. After cooked process content was decreased similarly like antioxidant activity, but enriched pasta showed better activity with control sample, in which these compounds were only in small amount. The best value in 5\% green barley pasta is probably due to higher amount of phenolic antioxidants such as phenolic acid derivatives, proanthocyanidins, quinones, and flavonoids. Statistically strong correlation $(p \leq 0.05)$ was observed in our study between total polyphenol content and DPPH method ( $\rho=0.914)$.

Total flavonoid content. Flavonoids are regarded as one of the most widespread groups of natural constituents found in plants (Suhartono et al., 2012). Total flavonoid content (Tab.3) in enriched pasta ranged from 0.05 to 0.41 , with the best results in 5\% green barley addition pasta. In control raw pasta was no detected presence of these compounds. After cooking the amount of flavonoids decrease rapidly (pasta with 1\% and $5 \%$ of green barley addition). Role of flavonoids in human health is supported by the ability of the flavonoids to induce human protective enzyme systems, and by a number of epidemiological studies suggesting protective effects against cardiovascular diseases, cancers, and other age-related diseases (Yao et al., 2004). Pasta enriched with green barley can effectively increase amount of flavonoids in human diet. Kamiyama and Shibamoto, (2012) reported that green barley leaves contain saponarin, flavonoid possesses potent antioxidant activities, which are determined by its inhibition of malonaldehyde formation from various lipids oxidized by UV light or Fenton's reagent.

Total chlorophyll content. Chlorophyll is very important natural colorant which has many health benefits such as anti-inflammatory, antiseptic and antioxidant. Pasta prepared with green barley addition (Tab. 3) showed not only 
better antioxidant activity but enriched pasta also for chlorophyll with compare to control sample without addition. The higher values of this natural colorant was detected in 5\% green barley pasta - raw and cooked. Chlorophyll from green barley had positive influence also for pasta color, which consumers evaluated in sensory evaluation positively, because nowadays we can observe big interest about foods prepare with natural colorants. Statistically strong correlation $(p \leq 0.05)$ was observed in our study between molybdenum reducing antioxidant power method and total chlorophyll content $(\rho=0.841)$.

Table 3. Total polyphenol, flavonoid and chlorophyll content in prepared pasta (dry matter)

\begin{tabular}{|c|c|c|c|}
\hline Sample & $\begin{array}{l}\text { Total polyphenol } \\
\text { [mg GAE/g] }\end{array}$ & 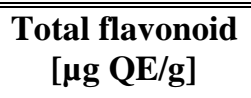 & $\begin{array}{l}\text { Total chlorophyll } \\
\text { [mg/g] }\end{array}$ \\
\hline $\begin{array}{l}\text { Control pasta raw } \\
\text { Control pasta cooked }\end{array}$ & $\begin{array}{l}0.19 \pm 0.01 \\
0.11 \pm 0.02\end{array}$ & $\begin{array}{l}- \\
-\end{array}$ & $\begin{array}{l}- \\
-\end{array}$ \\
\hline $\begin{array}{c}1 \% \text { green barley pasta } \\
\text { raw }\end{array}$ & $0.47 \pm 0.02$ & $0.05 \pm 0.001$ & $4.29 \pm 0.25$ \\
\hline $\begin{array}{c}1 \% \text { green barley pasta } \\
\text { cooked }\end{array}$ & $0.41 \pm 0.01$ & $0.01 \pm 0.001$ & $0.61 \pm 0.01$ \\
\hline $\begin{array}{c}\text { 3\% green barley pasta } \\
\text { raw }\end{array}$ & $0.61 \pm 0.02$ & $0.19 \pm 0.02$ & $9.48 \pm 0.01$ \\
\hline $\begin{array}{c}3 \% \text { green barley pasta } \\
\text { cooked }\end{array}$ & $0.49 \pm 0.01$ & $0.16 \pm 0.01$ & $0.64 \pm 0.01$ \\
\hline $\begin{array}{c}5 \% \text { green barley pasta } \\
\text { raw }\end{array}$ & $1.09 \pm 0.01$ & $0.41 \pm 0.03$ & $10.54 \pm 0.01$ \\
\hline $\begin{array}{c}5 \% \text { green barley pasta } \\
\text { cooked }\end{array}$ & $0.73 \pm 0.02$ & $0.29 \pm 0.02$ & $0.71 \pm 0.03$ \\
\hline
\end{tabular}

GAE- gallic acid equivalent; QE - quercetin equivalent \pm standard deviation

Sensory evaluation. Judges evaluated all prepared pasta regarding control sample overall as good. From 1\%, 3\% and 5\% pasta enriched with green barley powder (Fig. 1) was the best evaluated variant with 1\%, which was attractive for consumer from taste, smell and overall acceptability point of view. 3\% addition was also evaluated well, but many judges sign that in this variant felt unpleasant grassy aftertaste, similarly like in 5\% variant in which also judges unpleasant grassy aftertaste and smell. Biological activity was best in 5\% green barley pasta, but for food industry we recommend according to our results maximal percentage of addition $3 \%$, because higher percentage of addition unpleasant influence smell and aftertaste. Generally enriched pasta with green barley powder increase sensory properties of pasta mainly taste and color, which effective increase attractively of these products for consumers. 


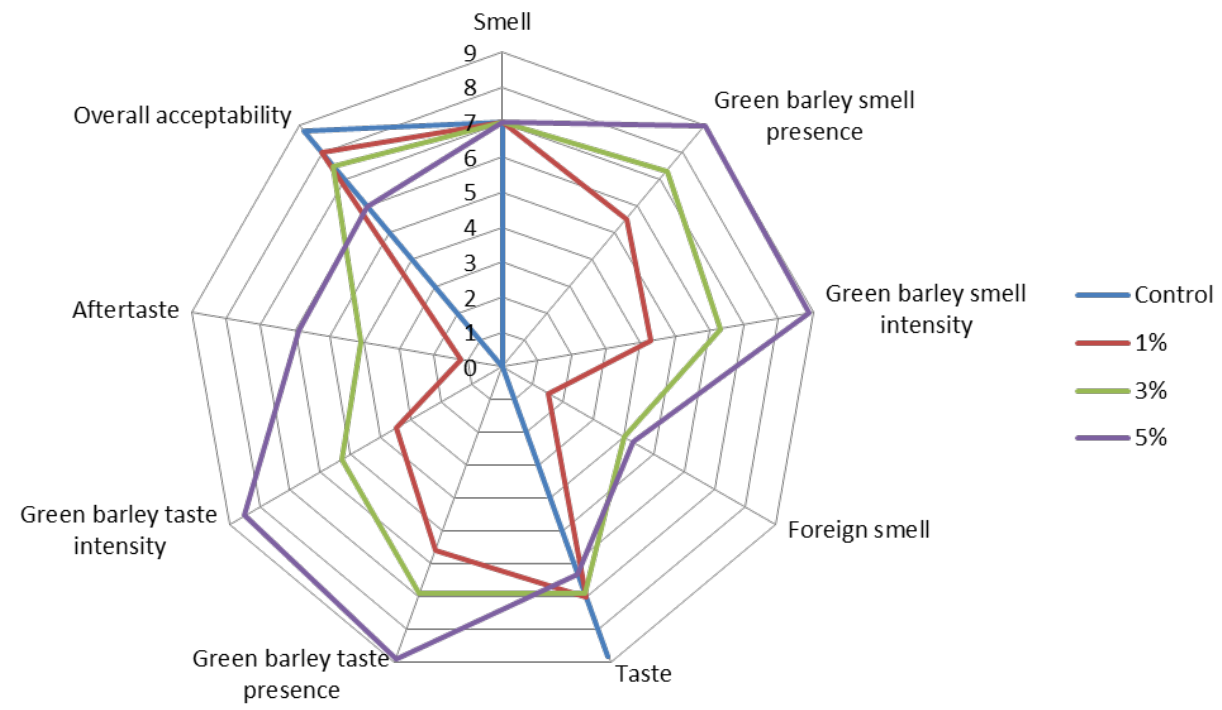

Figure 1. Sensory evaluation of prepared pasta (1\%, 3\%, 5\% - \% of green barley addition)

\section{CONCLUSION}

Green barley powder from young leaves being rich in phytochemicals and incorporation of these into pasta products will add health benefits. As consumption of pasta is becoming popular worldwide, this kind of pasta will supply essential nutrition as well as health benefits. Polyphenols, flavonoids and chlorophyll content in developed green barley based pasta were significantly higher than in control pasta. The developed functional pasta showed increase in phenolic content and antioxidant activity, but this content decreased slightly after cooking. Generally biological activity was best in 5\% green barley pasta, but for food industry we recommend according to our results maximal percentage of addition 3\%, because higher percentage of addition unpleasant influence smell and aftertaste. Thus it could be concluded that good quality nutrient rich pasta can be prepared with green barley addition.

Acknowledgment: The publication was prepared with the active participation of researchers involved in the International network AgroBioNet of the Institutions and researchers for realization of research, education and development program «Agrobiodiversity for improving nutrition, health and life quality» and within the project ITEBIO (ITMS 26220220115).

\section{ACKNOWLEDGEMENT}

This research is a part of project supporting by International Network Agrobionet of The Institutions and Researchers for realization of research, education and development program «Agrobiodiversity for improving nutrition, health and life quality» and within the project ITEBIO (ITMS 26220220115).

\section{REFERENCES}

BIERNACKA, B., DZIKI, D., GAWLIK-DZIKI, U., RÓZYLO, R. Physical, sensorial and antioxidant properties of common what pasta enriched with carob fiber. LWT - Food Science and Technology, 77:186-192, 2017.

BOROSKI, M., CAROLINA DE AGUIAR, A., BOENING, J.S., ROTTA, E.M., WIBBY, C.L., BONAFE, E.G., SOUZA, N.E., VISENTAINER, J.U. Enhancement of pasta antioxidant activity with oregano and carrot leaf. Food Chemistry, 125:696-70, 2011. KAMIYAMA, M., SHIBAMOTO, T. Flavonoids with potent antioxidant activity found in young green barley leaves. Journal of Agricultural and Food Chemistry, 60:60-67, 2012.

KIM, H., HONG, H., SHIN, K.S. Structure elucidation of an immunostimulatory arabinoxylan-type polysaccharide prepared from young barley leaves. Carbohydrate Polymers, 157:282-293, 2017.

LICHTENTHALER, H. L., WELLBURN, A. R. Determinations of total carotenoids and chlorophylls a and b of leaf extracts in 
different solvents. Biochemical Society Transactions, 2:591-592, 1983.

PAUliČKOVÁ, I., EHRENBERGEROVÁ, J., FIEDLEROVÁ, V., BABROVSKÁ, D., HAVLOVÁ, P., HOLASOVÁ, M., KOPÁČEK, J., OUHRABKOVÁ, J., PINKROVÁ, J., RYSOVÁ, J., VACULOVÁ, J., WINTEROVÁ, R. Evaluation of barley grass as a potential source of some nutritional substances. Czech Journal of Food Sciences, 2:65-72, 2006.

PRIETO, P., PINEDA, M., AGULAR, P. Spectrophotometric quantitation of antioxidant capacity through the formation of a phosphomolybdenum complex: specific application to the determination of vitamin E. Analytical Biochemistry, 269:337-341, 1999.

QUETTUER-DELEU, CH., GRESSEIR, B., VESSEUR, J. Phenolic compounds and antioxidant activities of buckwheat hulls and flour. Journal of Ethnopharmacology, 1-2:35-42, 2000.

SAS 2009. Users Guide Version 9. 2. SAS/STAT (r) SAS Institute Inc. Cary, NC, USA.

SESZYK, L., SWIECA, M., GAWLIK-DZIKI, V. Changes of antioxidant potential of pasta fortified with parley (Petroselinum crispum Mill.) leaves in the light of protein-phenolics interactions. Acta Scientarum Polonorum Technologia Alimentaria, 14:2936, 2015.

SINGLETON, V. L., ROSSI, J. A. Colorimetry of total phenolics with phosphomolybdic-phosphotungstic acid reagents. American Journal of Enology and Agricultural, 6:144-158, 1965.

SUHARTONO, E., VIANI, E., RAHMADHAN, M.A., SYAHUZI, G., RAKHMAN, M.F., INDRAWARDHANA, D. Total flavonoid and antioxidant activity of some selected medicinal plants in south Kalimantan of Indonesian. APCBEE Proceeding, 4: 235-239, 2012.

TAZRART, K., LAMACCHIA, C., ZAIDI, F. HAROS, M. Nutrient composition and in vitro digestibility of fresh pasta enriched with Vicia faba. Journal of Food Composition and Analysis, 47:5-8, 2016.

TEPE, B., SOKMEN M., AKPULAT H.A., SOKMEN A. Screening of the antioxidant potentials of six Salvia species from Turkey. Food Chemistry, 95: 200-204, 2006.

WHO/FAO. Diet, nutrition and the prevention of chronic disease. Report of a joint expert consultation World Health Organization Technical Report Series, 916: 1-149, 2003.

YAMAURA, K, TANAKA, R., BI, Y., FUKATA, H., OISHI, N., SATO, H. Protective effect of young green barley leaf on restraint stress-induced decrease in hippocampal brain-derived neurotrophic factor in mice. Pharmacognosy Magazine, 11:586592, 2015.

YAO, L.H., JIANG, Y.M., SHI, J., TOMÁS-BARBERÁN, F.A., DATTA, N., SINGANUSONG, R., CHEN, S.S. Flavonoids in food and their health benefits. Plant Foods for Human Nutrition, 59:113-122, 2004.

YEN, G. C., CHEN, H. Y. Antioxidant activity of various tea extracts in relation to their antimutagenicity. Journal of Agricultural Food Chemistry, 43:27-32, 1995.

Received / Primljen: 27.07.2017. Accepted / Prihvaćen: 24.12.2017. 